\section{Un sistema de asignación de órganos para trasplante que no considere las edades de donante y receptor es inicuo}

\author{
FERNANDO GONZÁLEZ ${ }^{1,2}$, XIMENA ROCCA $^{1,2}$
}

\section{An organ allocating system for transplantation that does not consider donor and recipient ages is not fair}

Background: Kidney transplantation is the best treatment for end stage kidney disease. The allograft allocation system considers immunological factors and time in waiting list, but not the age of donors or recipients, in spite that both have prognostic relevance. Aim: To study the fairness of the allograft allocation system considering the age of donors and recipients. Material and Methods: Based in the age distribution of donors and waiting list of patients for kidney transplantation, we constructed probability functions for receiving a graft as an allocation system based on age changes from a strict to a more lax criteria. Finally, we compared our model with the real transplants performed during 2012. Results: The probability distribution for receiving a kidney transplantation is displaced to the right compared with the age distribution of graft donors. This gap increases as the procuring hospitals enlist progressively older graft candidates without accepting older donors in parallel. An allocation system that maintains age parity between donors and recipients is fairer that other that allows lax criteria for the same allocation. This phenomenon is attenuated if the procurement acceptance criterion allows older donors. Conclusions: It is necessary to reduce the gap between donor and recipient ages for kidney transplantation to improve the fairness of the graft allocation system.

(Rev Med Chile 2015; 143: 1419-1425)

Key words: Kidney transplantation; Patient care planning; Unrelated donors; Waiting lists.

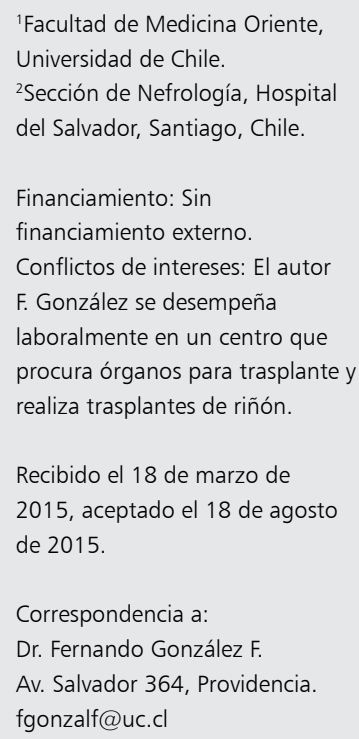

E 1 trasplante renal es el mejor tratamiento de la insuficiencia renal terminal ${ }^{1}$. Sin embargo, la limitante para aumentar la tasa de trasplantes en Chile es la escasez de donantes en relación al número de pacientes que están en lista de espera ${ }^{2}$. Cuando se genera un donante de órganos, el Instituto de Salud Pública (ISP) asigna los riñones a sus receptores basado en un sistema de puntaje que incluye la histocompatibilidad (sistema HLA), el tiempo de espera en la lista y el grado de sensibilización del potencial receptor o PRA ("Panel Reactive Antibodies"), que ponderan
$60 \%, 20 \%$ y $20 \%$, respectivamente. Adicionalmente, si el potencial receptores menor de 18 años, se le asigna mayor puntaje ${ }^{3}$.

Son determinantes de la sobrevivencia del injerto: la edad del donante, la del receptor y la disparidad de edades entre donante y receptor ${ }^{4-7}$ entre otros, por lo que llama la atención que el sistema de asignación de riñones no considere estos factores. Al mismo tiempo, es imprescindible que este $u$ otro sistema sean justos, equitativos y no discriminantes de ninguna forma para los pacientes enlistados. 
El objetivo de este trabajo es estudiar la equidad en la asignación de órganos para trasplante renal respecto de las edades del donante y del receptor y proponer eventuales medidas de mitigación en el caso que se encuentren variables perfectibles.

\section{Pacientes y Métodos}

Se obtuvo las edades de los donantes fallecidos de órganos del año $2011^{8}$ y de quienes se encontraban en lista de espera en el ISP a septiembre de 2012 (Dra. Susana Elgueta, comunicación personal) y, a partir de ellas, se construyó las distribuciones de probabilidad y edad de ambos grupos de personas mediante fórmulas estadísticas estándar y utilizando el programa Excel de Microsoft.

Dado la apariencia de los histogramas de edades observadas, se las consideró teniendo una distribución normal. Se modeló matemáticamentelas probabilidades de ser donante o estar en lista de espera en función de la edad de los sujetos, utilizando los promedios y desviaciones estándar dentro de una curva de distribución normal.

Con esas funciones de probabilidades y empleando una aproximación Bayesiana, se calculó la probabilidad de que pacientes en lista de espera recibieran un injerto renal en distintos escenarios, según variase el criterio de asignación de órganos (iguales edades y diferencias de 5 o 10 años entre ambos grupos de personas). En segundo término, para facilitar la visualización de los cambios de probabilidades de asignación de riñones, se calculó las probabilidades relativas de recepción en los distintos escenarios (iguales edades, diferencias de 5 o 10 años).

Lo anterior, también puede describirse como que se calculó la probabilidad de recibir un injerto según la edad del donante de órganos, según distintos criterios de asignación basados exclusivamente en los pares de edades entre donante y receptor, para todas las personas de la lista de espera para recibir un trasplante renal. Por ejemplo, si existieren dos receptores posibles, uno de 30 años y el otro de 60 años esperando la decisión de asignación de un donante de 50 años, y el criterio de asignación es que la diferencia de edades entre donante y receptor debe ser inferior a 10 años, la persona más joven tendrá menos probabilidad de recibir el injerto, pero si el criterio es hasta 20 años, las probabilidades de ambos sujetos se acercarán entre sí, lo mismo, si no existe criterios de exclusión de diferencias etarias entre esos pares.

Finalmente, se comparó el modelo con las edades de los pacientes efectivamente trasplantados durante el año 2012 obtenido del correspondiente Registro Nacional de Trasplantes del Instituto de Salud Pública de tal forma de deducir la distribución real de quienes esperan en lista de espera y, secundariamente, de los comportamientos y criterios de los centros que, efectivamente, procuran donantes renales.

\section{Resultados}

En el período estudiado, hubo 113 donantes y el número de candidatos a recibirlos eran 1.167, lo que da una probabilidad bruta de ser trasplantado de 19,4\% (226 riñones en los 1.167 pacientes enlistados en el ISP). Los donantes de órganos tenían 44,2 $\pm 14,0$ años de edad y los pacientes en lista de espera para trasplante renal 42,1 $\pm 14,5$ años (Tabla 1). La edad real de quienes recibieron un trasplante renal de donante fallecido durante el año 2012 fue 47,5 $\pm 14,3$ años.

Si se comparan las distribuciones de probabilidad, construidas a partir de los datos de la Tabla 1 de ambos grupos, se observa que la curva de los

\section{Tabla 1. Tabla de distribución de donantes de riñones y de pacientes en lista de espera en el período de estudio}

\begin{tabular}{|lcc|}
\hline $\begin{array}{l}\text { Grupo etario } \\
(\mathbf{x} \mathbf{)})\end{array}$ & $\begin{array}{c}\text { Lista de espera } \\
\left(\mathbf{f}_{\mathbf{i}}\right)\end{array}$ & $\begin{array}{c}\text { Donantes } \\
\left(\mathbf{f}_{\mathbf{i}} \mathbf{)}\right.\end{array}$ \\
\hline 15 o $<$ & 29 & 3 \\
\hline 16 a 24 & 69 & 17 \\
\hline 25 a 34 & 188 & 8 \\
\hline 35 a 44 & 279 & 21 \\
\hline 45 a 54 & 333 & 54 \\
\hline 55 a 64 & 221 & 9 \\
\hline$>65$ & 40 & 1 \\
\hline Sin dato & 8 & 0 \\
\hline Total general & 1.167 & 113 \\
\hline Promedio & 44,2 & 42,1 \\
\hline Desviación estándar & 14,0 & 14,5 \\
\hline
\end{tabular}


pacientes en lista de espera está desplazada hacia la derecha (Figura 1) y que ello se hace aún más patente si los centros de trasplante aumentan la edad máxima para que los pacientes opten a ser trasplantados en $5 \mathrm{o} 10$ años en promedio (Figuras 1 y 2). Lo anterior significa que si los centros de trasplante enlistan pacientes de mayor edad, manteniendo constante la distribución de edades de los donantes, se aumenta la probabilidad relativa de recibir un injerto renal a los enlistados de mayor edad y se la reduce a pacientes más jóvenes.

Cuando se decide, en base a la edad de donante y receptor, qué paciente recibirá un injerto, puede utilizarse un criterio de empate de edades, es decir, un donante de 40 años se asigna a un receptor de iguales 40 años. Otras opciones son el permitir algún rango de disparidad de edad entre donante y receptor, por ejemplo, 5 o 10 años, es decir, los riñones de ese donante hipotético de 40 años podrían ser asignados a pacientes de entre $35 \mathrm{y}$ 45 años o entre 30 y 50 años, respectivamente, lo cual podría dar más libertad a quienes asignan los injertos, dado que existe también otras variables de asignación que deben ser consideradas ${ }^{2}$.

En la Figura 3 puede verse el efecto sobre la probabilidad relativa de recibir un riñón usando el criterio restrictivo de asignación, es decir, conservando la igualdad de edades entre donante y receptor y, en comparación, si se utiliza un criterio de edades más laxo, 5 o 10 años de diferencias de
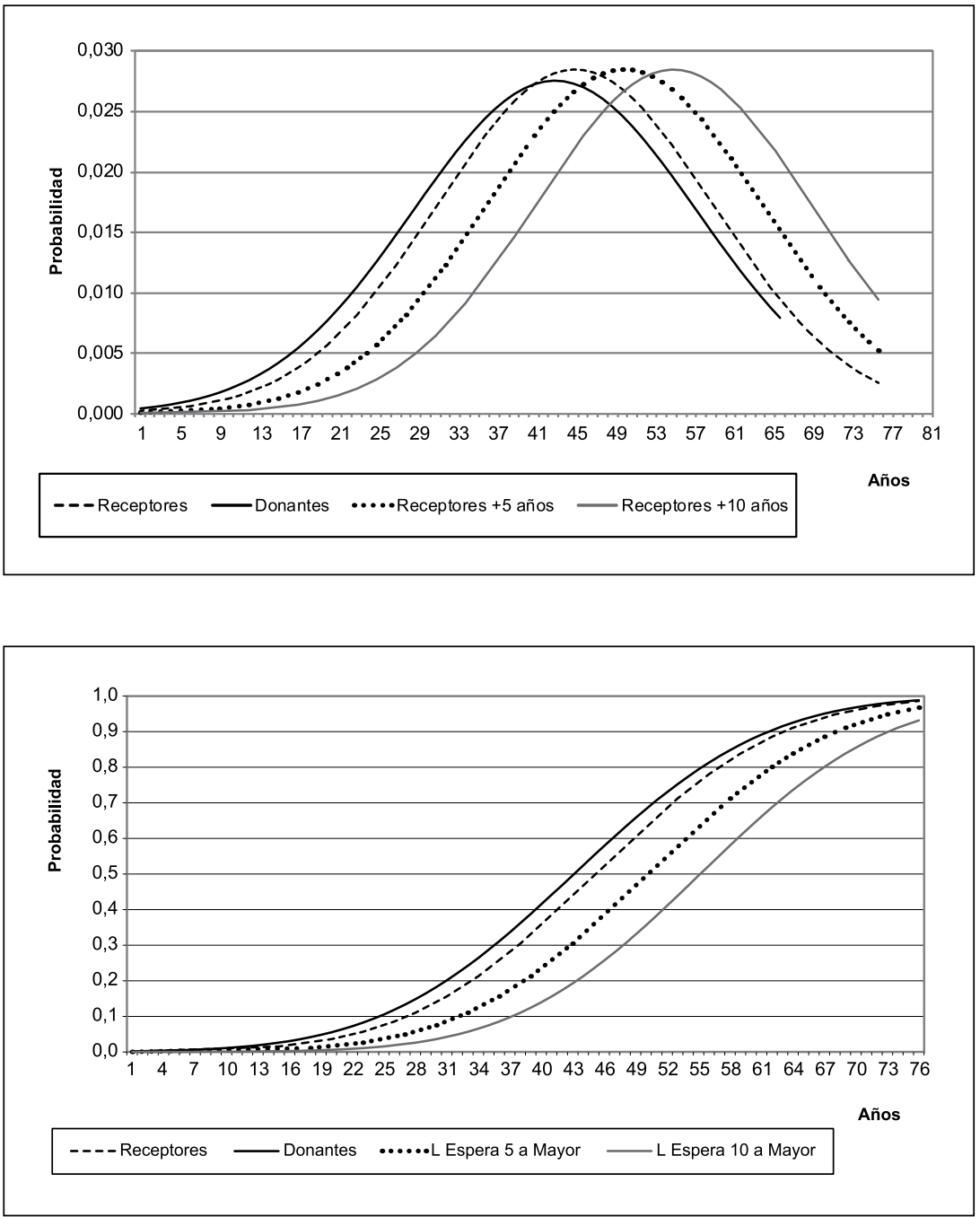

Figura 1. Distribuciones de probabilidades en función de la edad de donantes de riñón, pacientes en lista de espera actuales y si fueren, en promedio, 5 y 10 años mayores. Receptores: Receptores reales (Tabla 1). Donantes: Donantes reales (Tabla 1). Receptores +5 años: Distribución de edades si donantes son 5 años mayor. Receptores + 10 años: Distribución de edades si donantes son 10 años mayor.

Figura 2. Probabilidades acumuladas de recepción de riñones según edades de donantes actuales, lista de espera actual y si se estos fueran, en promedio, 5 y 10 años mayores. Receptores: Receptores reales (Tabla 1). Donantes: Donantes reales (Tabla 1). L Espera +5 años: Distribución de edades de pacientes en lista de espera 5 años mayor. Receptores +10 años: Distribución de edades de pacientes en lista de espera 10 años mayor. 


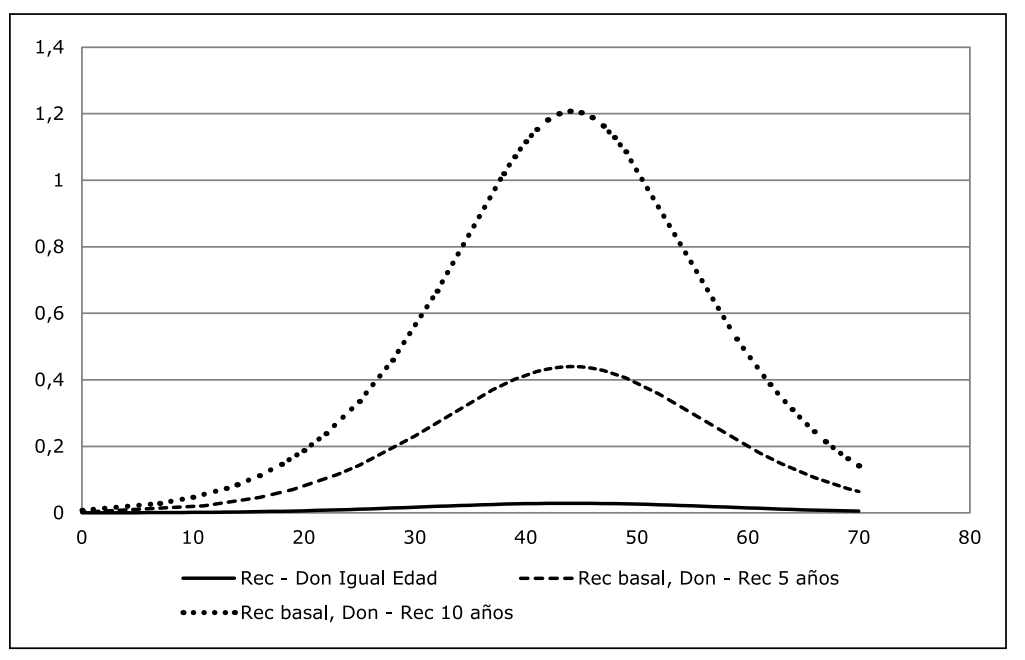

Figura 3. Probabilidad relativa de recepción de Injerto según criterio de diferencias edad entre Donantes y Receptores. Rec y Don igual edad: Distribución de probabilidad relativa si donantes y receptores tiene igual edad. Rec basal, Don-Rec 5 años: Distribución de probabilidad relativa si receptores son los en lista de espera actual (Tabla 1) y diferencia de edades entre donante y receptor es hasta 5 años. Rec basal, Don-Rec 10 años: Distribución de probabilidad relativa si receptores son los en lista de espera actual (Tabla 1) y diferencia de edades entre donante y receptor es hasta 10 años. edades, para decidir a qué persona de la lista de espera se asigna el órgano. Al comparar las curvas, es claro que, en comparación con el criterio restrictivo, que entrega probabilidades bastante similares para cualquier edad, el ampliar las diferencias de edad, tiende a favorecer a los pacientes de edades medias.

Ahora, si combinamos los escenarios de envejecimientos relativos de los donantes, los receptores, ambos y los criterios laxos, de 5 y 10 años de diferencias de edad, para la asignación de riñones, puede verse que aunque el criterio de laxitud de 5 años tiende a generar equidad en la asignación de órganos (respecto de un criterio de laxitud de 10 años), el envejecer la lista de espera, sin envejecer paralelamente a los donantes, independiente del criterio de laxitud, tiende a reducir la equidad, ya que los órganos procurados siempre tenderán a ser asignados a receptores de edades más altas (Figura 4). De lo anterior se desprende que para que el sistema de asignación de órganos sea equitativo, en el sentido de que la edad de algunos potenciales receptores no se constituya en una ventaja o una cortapisa para recibir un riñón, debería cumplirse con las siguientes condiciones:

1. Permitir la aceptación de donantes de mayores edades que las actuales.

2. No permitir la incorporación a potenciales receptores de riñones a la lista de espera de mayores edades que las actuales o posibilitarlo sólo en la medida que se también se acepte a donantes más añosos.
3. Mantener un criterio de laxitud de asignación de edades entre donante y receptor lo más acotado posible. Para esto, es obvio que, para que se cumpla, debe aumentarse tanto el número de donantes como el número de pacientes en lista de espera, de tal forma de maximizar la probabilidad de que existe pares de pacientes con "compatibilidad" de edades.

Finalmente, si se compara las distribuciones de edades de quienes esperaban en lista de espera, quienes donaron y quienes efectivamente recibieron los injertos, puede verse que: la edad de los donantes fue 42,1 $\pm 14,5$ años, de quienes esperaban en la lista $44,2 \pm 14,0$ años y quienes, efectivamente recibieron los injertos fue 47,5 \pm 14,3 años (Figura 5). No se encontró diferencias estadísticamente significativas entre los dos primeros grupos (donantes y lista de espera), pero sí entre cada uno de ellos y el grupo que recibió realmente los órganos: $\mathrm{p}=0,003$ y $\mathrm{p}=0,007$, respectivamente). Esto indica que, en la práctica, quienes enlistan a pacientes para trasplante están ingresando pacientes progresivamente mayores y/o no están aceptando donantes de órganos de edad "avanzada", respecto del criterio actual (Figuras 1, 4 y 5).

\section{Discusión}

El objetivo del trasplante de riñón es devolver la función renal a quien sufre de insuficiencia renal 
La asignación de órganos sin considerar la edad es inicuo - F. González et al

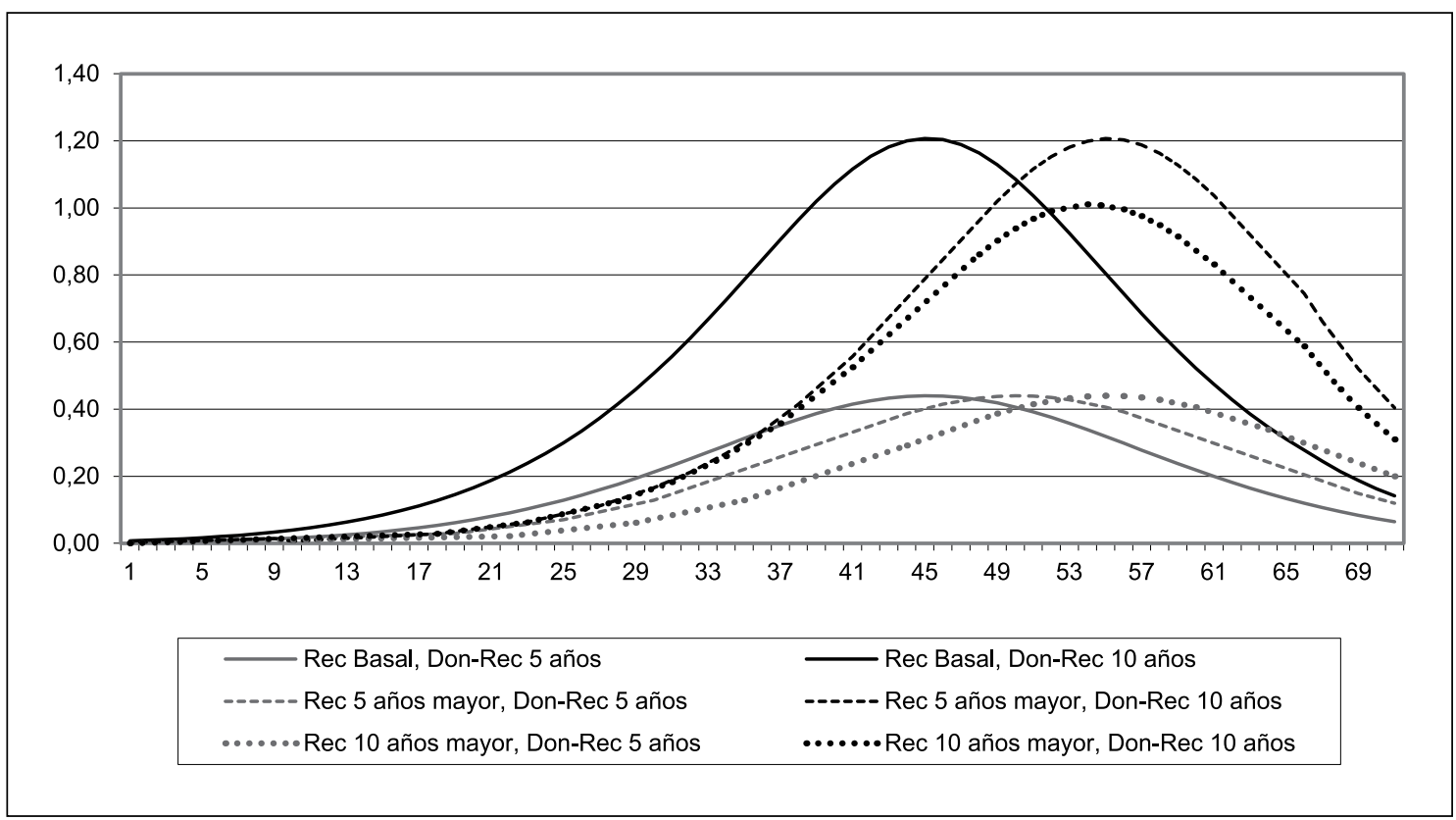

Figura 4. Probabilidad relativa de recepción de Injerto según criterio de diferencias edad entre Donantes y Receptores y según criterio de aceptación en lista de espera. Rec basal, Don-Rec 5 años: Distribución de probabilidad relativa si receptores son los en lista de espera actual (Tabla 1) y diferencia de edades entre donante y receptor es hasta 5 años. Rec basal, Don-Rec 10 años: Distribución de probabilidad relativa si receptores son los en lista de espera actual (Tabla 1) y diferencia de edades entre donante y receptor es hasta 10 años. Rec 5 años mayor, Don-Rec 5 años: Distribución de probabilidad relativa si receptores son 5 años mayores a los actuales y diferencia de edades entre donante y receptor es hasta 5 años. Rec 5 años mayor, Don-Rec 10 años: Distribución de probabilidad relativa si receptores son 5 años mayores a los actuales y diferencia de edades entre donante y receptor es hasta 10 años. Rec 10 años mayor, Don-Rec 5 años: Distribución de probabilidad relativa si receptores son 10 años mayores a los actuales y diferencia de edades entre donante y receptor es hasta 5 años. Rec 10 años mayor, Don-Rec 10 años: Distribución de probabilidad relativa si receptores son 10 años mayores a los actuales y diferencia de edades entre donante y receptor es hasta 10 años.

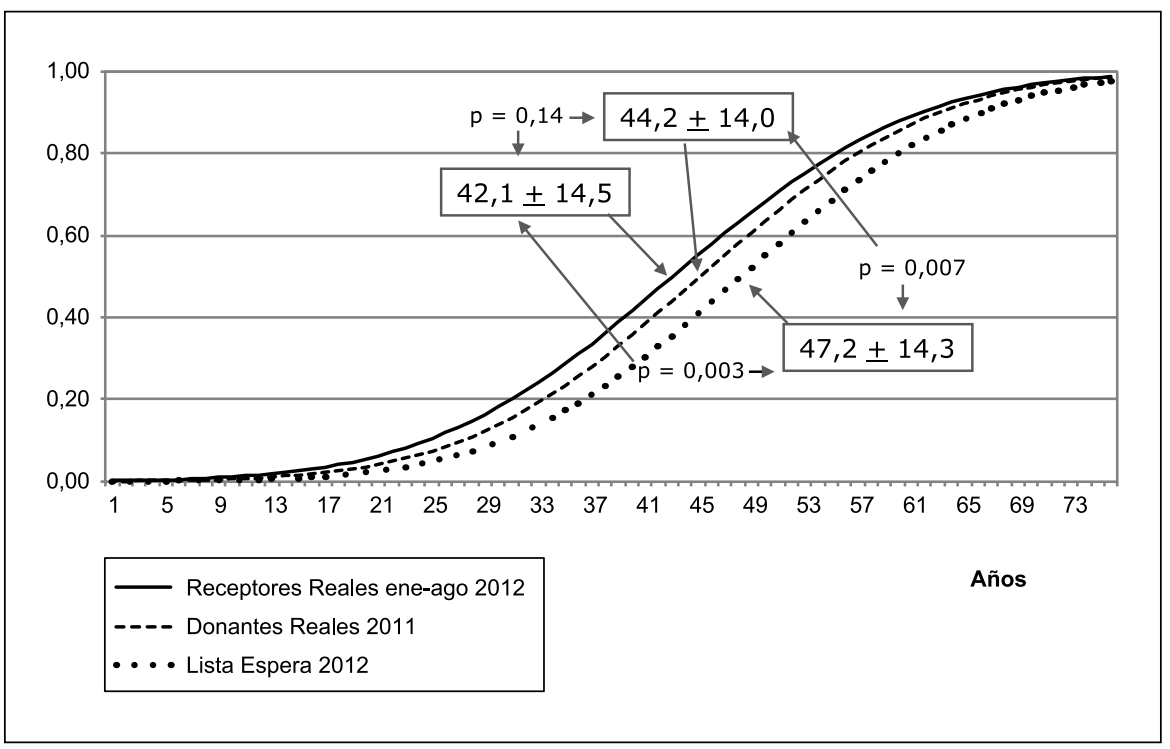

Figura 5. Distribuciones de edades de pacientes en lista de espera 2012, donantes efectivos 2012 y receptores efectivos de 2012. 
terminal y, con ello, reducirles la mayor mortalidad y morbilidad asociadas con la enfermedad renal crónica ${ }^{1,9}$. Esta mejoría funcional renal puede perderse por dos mecanismos: falla del órgano, por ejemplo, por rechazo del injerto, uropatía obstructiva, infecciones virales, reproducción de la enfermedad, toxicidad por fármacos, etc. o por muerte del sujeto con riñón funcionante. Si bien en ambas circunstancias el injerto se pierde, en la primera el paciente vuelve a diálisis y tiene la posibilidad de optar por otro injerto en el futuro, mientras que en el segundo escenario, el paciente fallece pero el injerto podría haber continuado funcionando. Los pacientes jóvenes tienden a perder los injertos por el primer mecanismo mientras que los mayores tienden a hacerlo por el segundo. Por lo anterior, puede producirse un conflicto en la asignación de riñones para trasplante, ya que lo que se busca es mantener al receptor sin necesidad de diálisis y prolongarle la vida, pero si el paciente fallece prematuramente, se pierde anticipadamente un riñón que podría haber continuado funcionando.

Los riñones para trasplante son un bien escaso, por ello es función de quienes asignan los órganos el maximizar la probabilidad que ese riñón funcione por largo tiempo y, de igual manera, prolongue lo más posible la supervivencia del receptor. Desde ese punto de vista, el utilizar riñones provenientes de donantes jóvenes sería lo más conveniente ${ }^{4-7}$, pero, el problema radica en que las donaciones son más escasas que lo que necesitamos como sociedad o, al revés, la demanda por riñones sobrepasa, por lejos, la oferta de donantes. Al mismo tiempo, el sistema de asignación debe ser justo, en el sentido de que todo paciente en la lista de espera tenga una probabilidad similar de recibir un órgano, sin sesgos de ninguna especie.

Nuestros resultados muestran que el sistema actual de asignación de órganos, mirado exclusivamente desde la óptica del criterio de asignación por edad, tiende a discriminar/postergar a los jóvenes y a favorecer, en forma relativa, a la población de mayor edad. Ello parece ocurrir, basado en los análisis de las curvas de probabilidades, porque se van incorporando sujetos de edades cada vez mayores a la lista de espera. Pero, a juzgar por la edad promedio de los donantes de nuestro país, y considerando que la primera causa de muerte en Chile es cardiovascular, pareciera que se tiende a evitar el procurar pacientes adultos mayores o con comorbilidades (criterio expandido), de tal forma que la población > 65-70 años rara vez o prácticamente nunca recibirá riñones de pacientes de edades similares, pero sí serán competencia para donantes jóvenes. Si bien es cierto se ha intentado incentivar este tipo de donación, pareciera ser que no se ha incorporado para nada en los centros de procuramiento, considerando que sólo hemos incrementado la edad de los donantes de manera marginal.

Este comportamiento sesgado en la asignación de riñones, que es probable que ni siquiera sea intencional ni conocido, no es compartido en todas partes. De hecho, el "Eurotransplant Senior Program" asigna los riñones de donantes de $>65$ años a receptores de edades similares desde el año $1999^{10}$ basado en la política de "old for old", es decir, donantes añosos para receptores añosos. Sus resultados son razonables y comparables a criterios de asignación de riñones de donantes jóvenes a receptores $>65$ años $^{11,12}$, especialmente al compararlos con el continuar en diálisis ${ }^{1}$.

Se hace necesario entonces aceptar donantes añosos y destinarlos preferentemente a receptores de edades similares, para de esta forma poder asignar los riñones de donantes más jóvenes a quienes hoy ven mermada su probabilidad de recibir un injerto. De lo contrario, puede darse la situación extrema e indeseable de reemplazar una política exitosa, como es la "Old for Old" por otra de "All for Old", que tiende a discriminar a los más jóvenes (“... and No Young at All”).

En suma, el sistema de asignación de órganos de pacientes fallecidos en Chile favorece a los receptores de mayor edad y perjudica a los más jóvenes. Esto debiera ser corregido porque genera inequidad.

\section{Referencias}

1. Wolfe RA, Ashby VB, Milford EL, Ojo AO, Ettenger RE, Agodoa LYC, et al. Comparison of mortality in all patients on dialysis, patients on dialysis awaiting transplantation, and recipients of a first cadaveric transplant. N Engl J Med 1999; 341: 1725-30.

2. Elgueta S e Instituto de Salud Pública de Chile. Registro Nacional de Trasplante Renal 2013. http://www.nefro. cl/phocadownload/congresos/Congreso2013/presentaciones/viernes\%2015/1220\%20Dra.\%20Susana\%20 Elgueta\%20Tx\%202013\%20\%2013-112013\%20final\%20 a\%20congreso.pdf. (Acceso el 27 de noviembre de 2014). 
3. Domínguez J. Sistema de Distribución de Órganos en Chile: Propuesta para una Modificación de la Distribución de Riñones de Donantes Cadavéricos para Trasplante. Rev Med Clin Condes 2010; 21 (2) 179-85.

4. Laging M, Kal-van Gestel JA, van de Wetering J, Ijzermans JN, Weimar W, Roodnat JI. The relative importance of donor age in deceased and living donor kidney transplantation. Transplant Int 2012; 25: 1150-7.

5. Park KS, Shin JH, Jang HR, Lee JE, Huh WS, Kim YG, et al. Impact of donor kidney function and donor age on poor outcome of living-unrelated kidney transplantation (KT) in comparison with living-related KT. Clin Transplant 2014; 28 (9): 953-60.

6. Tasaki M, Saito K, Nakagawa Y, Ikeda M, Imai N, Narita I, et al. Effect of donor-recipient age difference on longterm graft survival in living kidney transplantation. Int Urol Nephrol 2014; 46 (7): 1441-6.

7. Colussi G, Vergara M, Wang Z, Roland R. Risk factors associated with efficacy outcomes in kidney transplantation: analysis of a contemporary cohort of patients from the A2309 trial. Clin Nephrol 2015 Mar 27. [Epub ahead of print] DOI 10.5414/CN108568.

8. Memoria de la Corporación de Trasplante 2011. http:// www.nefro.cl/web2/articulo.php?id=128. (Acceso el 27 de noviembre de 2014).

9. Go AS, Chertow GM, Fan D, McCulloch CE, Hsu CY. Chronic Kidney Disease and the Risks of Death, Cardiovascular Events, and Hospitalization. N Engl J Med 2004; 351: 1296-305.

10. Eurotransplant Senior Program https://www.eurotransplant.org/cms/index.php?page=esp. (Acceso el $11 \mathrm{de}$ diciembre de 2014).

11. Pierobon E, Sandrini S, De Fazio N, Rossini G, Fontana I, Boschiero L, et al. Optimizing utilization of kidneys from deceased donors over 60 years: five-year outcomes after implementation of a combined clinical and histological allocation algorithm. Transpl Int 2013; 26: 833-41.

12. Al-Shraideh Y, Farooq U, Farney AC, Palanisamy A, Rogers J, Orlando G, et al. Influence of recipient age on deceased donor kidney transplant outcomes in the expanded criteria donor era. Clin Transplant 2014; 28: 1372-82. 